Eduardo Alberto Cusce Nobre

\section{$p$ \\ OLÍTICAS DE REABILITAÇÃO DO PATRIMÔNIO CULTURAL URBANO: AVALIAÇÃO DA EXPERIÊNCIA DOS ÓRGÃOS DE PROTEÇÃO HISTÓRICA PAULISTANOS}

\title{
RESUMO
}

Atualmente, um dos temas que mais se destaca na atuação prática e nas discussões teóricas entre arquitetos e urbanistas é o das políticas urbanas de reabilitação do patrimônio cultural. Este artigo procura analisar o resultado da implementação dessas políticas na cidade de São Paulo, a partir da análise da experiência prática dos seus órgãos de proteção, principalmente no que tange ao patrimônio arquitetônico-urbano. Para tanto, em primeiro lugar, busca definir o conceito de patrimônio cultural a partir da revisão teórica sobre o tema. Num segundo momento, analisa a evolução dessas políticas de sua reabilitação em alguns países do mundo e seus principais resultados, para depois aprofundar-se no estudo de caso. A partir da análise da atuação dos principais órgãos de proteção ao patrimônio cultural do município, o Departamento do Patrimônio Histórico e o Conselho Municipal de Preservação do Patrimônio Histórico, Cultural e Ambiental Urbano de São Paulo, busca compreender os limites e as potencialidades da implementação dessa política no contexto paulistano.

\section{Palavras-CHAVE}

Planejamento urbano. Políticas públicas urbanas. Patrimônio cultural urbano. Reabilitação urbana. São Paulo (município). 


\section{POLICIES FOR THE URBAN \\ CULTURAL HERITAGE \\ REHABILITATION: ASSESSMENT \\ ON THE EXPERIENCE OF THE \\ CITY SÃO PAULO HISTORICAL PRESERVATION AGENCIES}

\section{AbStract}

Presently, urban policies for the rehabilitation of cultural heritage is one of the most prominent themes both in practical action and in theoretical discussion between architects and urban planners. This article analyzes the results of the implementation of these policies in the city of São Paulo, based on the analysis of its preservation authorities' practical experience, specially related to the urban-architecture realm. First, it seeks to define the concept of cultural heritage based on theoretical review. Second, it analyzes the evolution of cultural heritage rehabilitation policies in some countries and its main results, to later deepen the case study. Based on the analysis of the main cultural heritage protection municipal authorities' actions, the Department of Historic Heritage and the Municipal Council for Preservation of the Historical, Cultural and Environmental Heritage of São Paulo, it seeks to understand the limits and potentialities of the implementation of these policies in the São Paulo context.

\section{Keywords}

Urban planning. Urban policies. Cultural heritage. Urban rehabilitation. São Paulo (City). 


\section{A evolução do CONCEito de patrimônio CULTURAL}

Apesar de a discussão sobre o patrimônio cultural como nós conhecemos hoje ser uma preocupação recente no Brasil, datada de meados do século XX, a evolução desse conceito e das práticas para sua proteção e conservação remontam à Europa do Renascimento.

Françoise Choay, em seu livro A alegoria do patrimônio, afirma que a palavra patrimônio cultural designa um bem destinado ao usufruto de uma comunidade, constituído por uma diversidade de objetos que se congregam por seu passado comum: obras materiais, obras-primas de belas-artes, trabalhos e produtos resultados de todas as técnicas e saberes dos seres humanos, que apresentam significado cultural para essa ou para as demais comunidades (CHOAY, 2001, p. 11).

Segundo a autora, a evolução desse conceito inicia-se no Renascimento, com a definição de monumento, que tinha como função primordial difundir os valores de uma determinada sociedade ou localidade. Ela chama a atenção para a atuação do Papa Martinho V na consolidação deste conceito, pois esse pontífice teria se utilizado da construção de diversos monumentos em Roma para promover a recuperação simbólica do seu passado histórico e a valorização do seu presente naquele momento, tendo em vista o retorno da sede do papado da cidade francesa de Avignon para a Itália.

A autora comenta que a palavra monumento vem do latim monere, que significa lembrar. Dessa forma, a função do monumento seria a de um memorial e que a natureza afetiva de seu propósito era essencial, pois "não se trata de apresentar uma informação neutra, mas de tocar, pela emoção, uma memória viva" (CHOAY, 2001, p. 18). Nesse sentido, chama-se monumento tudo que foi edificado por uma comunidade de indivíduos que rememora ou faz com que outras gerações de pessoas rememorem acontecimentos, sacrifícios, ritos ou crenças.

Esse conceito passou por uma transformação na época da Revolução Francesa, que também muito se utilizou da construção de monumentos como forma de afirmação da identidade de um novo Estado nacional. Com relação às edificações e monumentos que simbolizavam o Ancien Régime, Choay afirma que o Governo Revolucionário mudou de atitude. Em um primeiro momento, sua ação foi a de destruição de todos os bens que lembrassem a monarquia. Mas, com o passar do tempo, esse governo percebeu que o grande valor financeiro desses bens poderia ajudar a financiar a construção desse novo Estado nacional. Procedeu então a desapropriação dos bens da coroa, da nobreza e da Igreja, que passaram a fazer parte do Patrimônio Nacional, surgindo assim a noção de patrimônio pelo seu valor financeiro, pois o significado dessa palavra que vem do latim tem o sentido de herança ou legado, já que pater é "pai" e monium é "recebido", ou seja, aquilo que é recebido do pai. 
Assim sendo, Choay afirma:

O valor primário do tesouro assim devolvido para o povo é econômico [...] Eles transformaram o status das antiguidades nacionais em valor de troca, em bens materiais. Sob o risco de prejuízo financeiro ao erário público eram necessárias a sua preservação e manutenção. (CHOAY, 2001, p. 98).

A necessidade de preservação desses bens materiais e de seu valor de troca ocasionou na França a criação, em 1837, da Comissão dos Monumentos Históricos, o primeiro órgão moderno com a função de proteger e conservar o patrimônio. Da mesma forma, vários outros países foram criando, ao longo dos séculos XIX e XX, seus órgãos de proteção ao patrimônio.

Apesar disso, o grande problema do patrimônio cultural privado constituiu-se, e ainda constitui-se, na perda do direito do proprietário de dispor livremente de seus bens em benefício público, o que muitas vezes ocasiona oposição à sua conservação e proteção. Isso, contudo, não fez com que essas ações fossem diminuídas, pois, conforme Choay:

as ameaças permanentes que pesam sobre o patrimônio não impedem um amplo consenso em favor de sua conservação e de sua proteção, que são oficialmente defendidas em nome dos valores científicos, estéticos, memoriais, sociais e urbanos, representados por esse patrimônio nas sociedades industriais avançadas. (CHOAY, 2001, p. 17).

Posteriormente, o conceito de patrimônio foi evoluindo e sendo disseminado pelas Cartas Patrimoniais, documentos elaborados por entidades, estudiosos e profissionais relacionados a essa área e que são referendados pelos órgãos de preservação de diversos países.

A Carta de Atenas, documento resultante do Congresso Internacional de Arquitetura Moderna, ocorrido nesta cidade em 1931, afirma no seu capítulo sobre patrimônio histórico que os valores arquitetônicos devem ser salvaguardados (edifícios isolados ou conjuntos urbanos), pois são testemunhos preciosos do passado e devem ser respeitados pelo seu valor histórico, plástico, e que aqueles que os detêm são encarregados de sua proteção e preservação (IPHAN, 2001).

Em que pese a ingerência de Le Corbusier na elaboração dessa Carta e de sua visão iconoclasta com relação à arquitetura do passado, o fato é que a questão do patrimônio histórico foi contemplada. Isso decorre da influência do Encontro do Escritório Internacional de Museus na Sociedade das Nações, que ocorreu naquela cidade no mesmo período. Esse encontro elaborou uma segunda Carta de Atenas, especificamente sobre a questão do patrimônio histórico, definindo princípios importantes com relação às práticas para a sua preservação e proteção, como: a manutenção da sua utilização para ajudar na sua conservação; a necessidade de legislação e administração que sobreponham o direito coletivo ao da propriedade privada do bem patrimonial; a importância da manutenção das características da vizinhança do bem para sua valorização; e a necessidade da cooperação técnica internacional (ESCRITÓRIO..., 2001).

Segundo Choay (2001), no pós-guerra o conceito de patrimônio histórico ampliou muito, incluindo todas as formas de construção, desde as eruditas às populares, das urbanas às rurais, edifícios públicos ou privados, tudo que 
A Unesco tem como um de seus objetivos a salvaguarda do patrimônio cultural e a preservação das identidades e tradições culturais, literárias e orais. apresentasse significado cultural para determinada comunidade ou até internacionalmente.

A Carta de Veneza, escrita nessa cidade em 1964 a partir do encontro do Instituto de Conservação de Monumentos e Sítios (Icomos), ampliou a ideia de patrimônio, do edifício isolado para o sítio urbano ou rural, que dá testemunho de uma civilização particular (ICOMOS, 2001). A partir de então, a lista do Patrimônio Mundial da Organização das Nações Unidas para a Educação, a Ciência e a Cultura (Unesco) ${ }^{1}$ passou a conter, além de edifícios isolados, parte do tecido físico de aglomerados urbanos, rurais, de bairros, de cidades e até de conjuntos de cidades.

Nas cidades latino-americanas, a adaptação do conceito de patrimônio para sua realidade foi definida pela Carta de Quito, promovida pela Organização dos Estados Americanos (OEA) em 1967. Essa Carta chamava a atenção para o potencial econômico dos bens patrimoniais da região no seu aproveitamento para o desenvolvimento do turismo (OEA, 2001).

Por fim, a Carta de Burra, promovida pela seção australiana do Icomos em 2013, trouxe a definição de vários termos relacionados ao patrimônio cultural, de suma importância para sua conceituação internacional, principalmente no que tange aos dois conceitos abaixo (ICOMOS, 2013):

- Conservação: 0 ato de manter a significância cultural de um lugar, promovendo seus valores estéticos, históricos, científicos, sociais e espirituais para gerações passadas, presentes e futuras;

- Restauração: obras ou técnicas para retornar o local para o estado anterior, retardando a sua degradação.

Assim, se a evolução do termo "patrimônio histórico" estava relacionada no passado à ideia de valorização da cultura nacional, advinda da formação dos estados-nações, a ideia do patrimônio cultural atual está relacionada a conceitos mais abrangentes, que no seu sentido mais amplo envolvem organismos internacionais e no mais restrito, as comunidades locais.

A Conferência Geral da Unesco, de 1972, definiu a importância da proteção do patrimônio mundial, destacando naquele momento tanto o patrimônio cultural, fruto da ação humana, quanto o natural, assim como a integração entre os dois. Segundo a Convenção para a Proteção do Patrimônio Mundial, Cultural e Natural, documento resultante dessa conferência, são considerados como patrimônio cultural (UNESCO, 1972):

- Os monumentos: obras arquitetônicas, de escultura ou de pintura monumentais, elementos de estruturas de caráter arqueológico, inscrições, grutas e grupos de elementos com valor universal excepcional do ponto de vista da história, da arte ou da ciência;

- Os conjuntos: grupos de construções isoladas ou reunidas que, em virtude de sua arquitetura, unidade ou integração na paisagem, têm valor universal excepcional do ponto de vista da história, da arte ou da ciência;

- Os locais de interesse: obras do Homem, ou obras conjugadas do Homem e da natureza, e as zonas, incluindo os locais de interesse arqueológico, com um valor universal excepcional do ponto de vista histórico, estético, etnológico ou antropológico. 
O capítulo da Educação, Cultura e Desporto da Constituição Federal de 1988 adotou o princípio do patrimônio cultural como um direito da população, assim como o dever do Estado, em conjunto com a sociedade, pela sua proteção

(BRASIL, 1988). Segundo o artigo 216, ele pode ser bens de natureza material e imaterial, portadores de referência à identidade, à ação, à memória dos diferentes grupos formadores da sociedade brasileira, nos quais se incluem:

I. As formas de expressão;

II. Os modos de criar, fazer e viver;

III. As criações científicas, artísticas e tecnológicas;

IV. As obras, objetos, documentos, edificações e demais espaços destinados às manifestações artístico-culturais;

V. Os conjuntos urbanos e sítios de valor histórico, paisagístico, artístico, arqueológico, paleontológico, ecológico e científico.

Para efeito deste trabalho, enfocaremos no item $\mathrm{V}$, que se detém sobre o patrimônio cultural urbano, sendo constituído de obras arquitetônicas isoladas ou em conjuntos de valor histórico e paisagístico.

\section{As EXPERIÊNCIAS INTERNACIONAIS DE REABILITAÇÃO DO PATRIMÔNIO CULTURAL URBANO}

A partir do momento em que ocorreu a ampliação do conceito de patrimônio histórico de edifícios isolados e monumentos para parte do tecido urbano, bairros inteiros, e até cidades, vários governos municipais, regionais e nacionais passaram a elaborar políticas de intervenção urbana sobre as áreas patrimoniais, seguindo as definições e as orientações dos órgãos de proteção que foram surgindo a partir das décadas de 1960 e 1970 (OLIVEIRA, 2009).

A conscientização dessa necessidade surgiu a partir dos efeitos nocivos dos processos de renovação urbana pelos quais várias cidades passaram a partir da década de 1950. Baseados nos ideais modernistas promovidos pelos Congressos Internacionais da Arquitetura Moderna e influenciados pelo forte desenvolvimento imobiliário do pós-guerra, várias cidades, principalmente nos países centrais, passaram a promover a renovação do seu tecido urbano e social com a abertura de novas frentes de expansão imobiliária (RAPKIN, 1980; OECD, 1983; NOBRE, 1994).

Ações como essas ocasionaram fortes reações populares nos Estados Unidos e em alguns países da Europa na década de 1960 (RAPKIN, 1980; SUSSKIND; ELLIOTT, 1983). 0 ambiente de efervescência cultural e manifestação política que essas cidades tiveram fez com que vários governos municipais revissem a forma como as intervenções públicas eram realizadas em áreas urbanas, passando a adotar a reabilitação das áreas urbanas, ou seja, a implementação de projeto de melhorias e de recuperação do ambiente urbano, sem promover a destruição do seu tecido físico e social.

É nesse contexto que a proteção e a conservação de áreas históricas começam a ser o enfoque das políticas urbanas em várias das cidades na Europa, que 
passam por processos semelhantes nesse período, como Amsterdam, Bolonha, Madri, Rotterdam e Veneza (APPLEYARD, 1979).

Para tanto, foi bastante importante a aproximação das políticas de proteção com o urbanismo e o planejamento urbano, destacando-se o papel do arquiteto italiano Gustavo Giovannoni, que estabeleceu uma metodologia para intervenções em áreas urbanas de interesse para a preservação (OLIVEIRA, 2009; KÜHL, 2012). Sua influência é sentida na Carta de Restauro Italiana, de 1972, que estabelecia o conceito de Centro Histórico, prevendo, além da conservação física do organismo urbanístico, a necessidade de um adequado planejamento físico e territorial para prever desenvolvimentos futuros.

Seguindo as recomendações da Carta de Restauro Italiana, a cidade de Bolonha, sob o comando do Partido Comunista Italiano, promoveu a reabilitação de seu centro histórico e a preservação do seu patrimônio cultural entre 1969 e 1977, através da conjugação do Plano de Conservação do Centro Histórico, de 1969 (Piano di Salvaguardia del Centro Storico), com o Plano de Habitação de Interesse Social, de 1973 (Piano di Edilizia Popolare).

A partir dos estudos de morfologia urbana desenvolvidos pelos arquitetos Saverio Muratori e Pier Luigi Cervellati, foi desenvolvido um projeto de intervenção quadra a quadra, conforme Figura 1, restaurando o casario histórico dos artesãos renascentistas e adaptando-os para moradias de estudantes, idosos e famílias dos trabalhadores do centro (CERVELLATI, 1979).

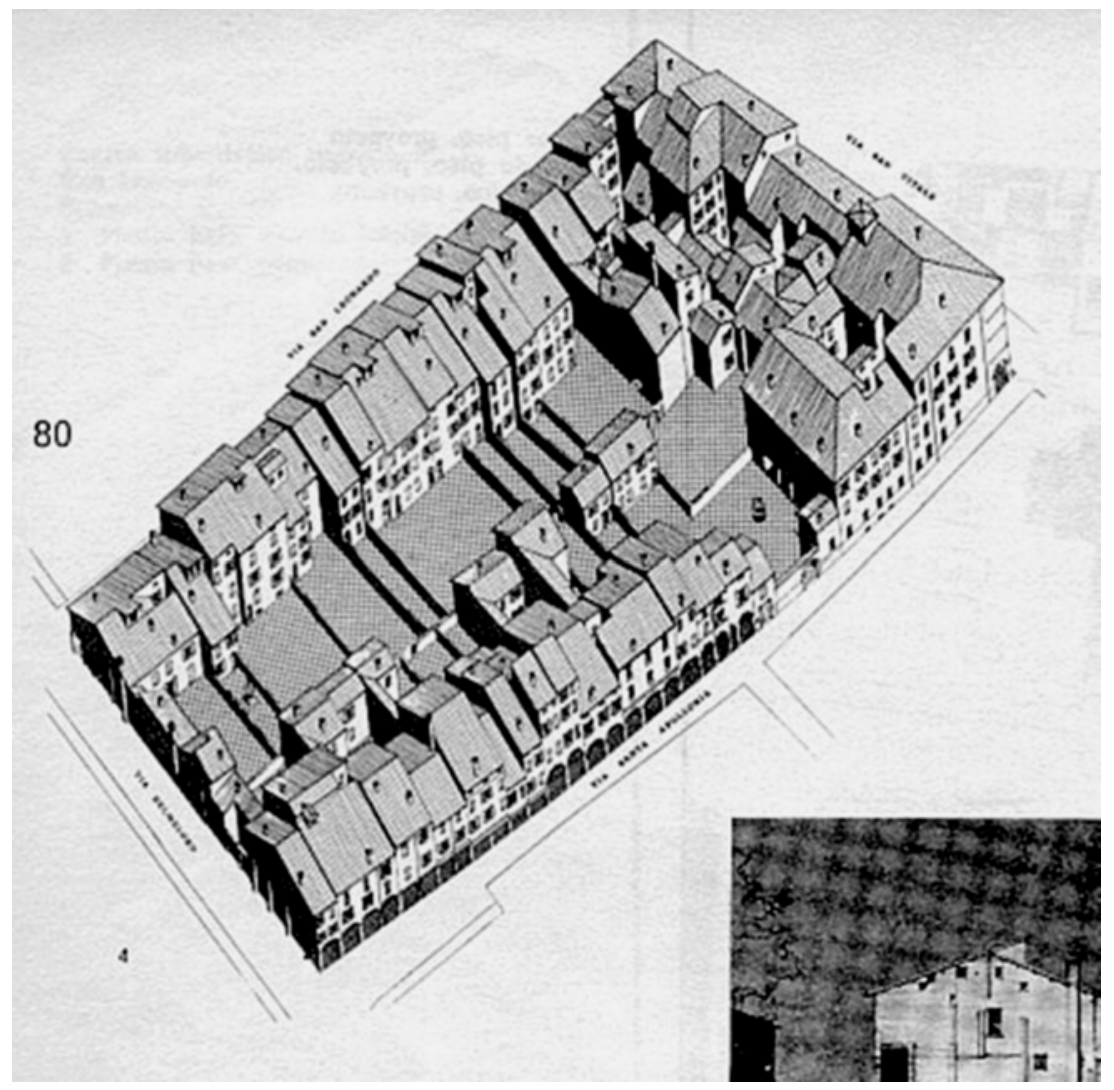

A experiência de conservação e restauro do Centro de Bolonha foi uma das mais bem-sucedidas. Apesar de originalmente a prefeitura comunista pretender desapropriar boa parte dos imóveis do centro, questões orçamentárias e a oposição política na Câmara Municipal fizeram com que a municipalidade optasse por financiar o restauro dos imóveis privados, mediante cessão de seu uso à municipalidade ou a definição máxima do valor de seu aluguel por um determinado período por parte dos proprietários.

Em 1977, o Plano de Habitação Social tinha conseguido (CERVELLATI, 1979):

1. Aquisição de edifícios no valor de dois bilhões de liras italianas;

Figura 1 - Proposta de remodelação de um quarteirão de Bolonha Fonte: Cervellati (1977). 
2 O PLD equivale à nossa Outorga Onerosa do Direito de Construir. Foi instituído na revisão do Código de Urbanismo de 1975 , com a finalidade de combater a especulação imobiliária,

incentivar a reciclagem das construções e prover de fundos os governos locais, através da cobrança do potencial construtivo acima do valor de um e meio para Paris e um para as outras regiões da França. Nos anos 1980 ele foi descentralizado e deixou de existir a partir da promulgação da Lei de Solidariedade e Renovação Urbana, de 2000 (Lei $n^{\circ} 1208$, de 13 de dezembro de 2000)

3 "Gentrificação" é uma tradução livre do termo gentrification. Sua origem vem do substantivo gentry, que significa a classe social bem abaixo da nobreza. Glass utilizou esse termo pela primeira vez em 1964 para identificar o processo pelo qual ocorria a substituição da classe trabalhadora pela classe média em bairros tradicionalmente operários. Smith (2006) atualizou esse trabalho identificando a transição de um processo localizado e espontâneo para uma estratégia intencional de intervenção urbana das municipalidades em escala global.
2. Renovação de 200 apartamentos para 500 pessoas, financiados parcialmente pela prefeitura e pelas agências nacionais de habitação;

3. Construção de centros de serviços sociais (escolas, centros de saúde, áreas de lazer) com um orçamento de 2,5 bilhões de liras italianas;

4. Restauro de monumentos históricos com um orçamento de 750 milhões de liras italianas.

Na França, o ministro da Cultura André Malreaux instituiu uma lei em 1962 (FRANÇA, 1962), que ficou conhecida como Lei Malreaux, criando os Secteur Sauvegardé, para os quais os municípios deveriam elaborar um plano de salvaguarda e que poderiam se utilizar de recursos provenientes de incentivos fiscais propostos por essa lei ou de recursos provenientes do fundo arrecadado pela aplicação do Teto Legal de Densidade (PLD, do francês Plafond Legal de Densitè $^{2}$ (CIPRIANO, 2018).

Nos Estados Unidos, a promulgação do National Heritage Preservation Act, de 1966, estabeleceu o sistema de Preservação do Patrimônio Cultural Nacional, possibilitando aos estados e municípios a elaboração de políticas de preservação cultural. Em função da perda econômica no valor de troca dos imóveis preservados, esse país desenvolveu mecanismos de compensação econômica aos proprietários desses imóveis como incentivo à sua conservação.

Desde 1968, as resoluções 74-79 da Lei de Zoneamento da cidade de Nova Iorque possibilitam aos proprietários de imóveis preservados a alienação do potencial construtivo, não utilizado para outros imóveis sem interesse histórico (HISTORIC..., 1971). Esse mecanismo ficou conhecido como Transferência do Direito de Construir (TDR, do inglês Transfer of Development Rights) e sua utilização foi amplamente defendida por diversos estudiosos da área, como o advogado estadunidense John Costonis, que propôs sua ampla utilização para viabilizar a preservação do centro histórico de Chicago (COSTONIS, 1974).

Se nos anos 1960 e 1970 as políticas urbanas tinham como objetivo a reabilitação do patrimônio cultural, com a preservação dos tecidos físicos e sociais de áreas históricas das cidades, a partir da ascensão do neoliberalismo nos anos 1980 e 1990 essas políticas se voltaram novamente para a renovação física e social dos centros urbanos, ocasionando impactos sociais e culturais negativos. A valorização simbólica e financeira que vários projetos ocasionaram nessas áreas resultou na expulsão da população mais pobre, processo que nesse período ficou conhecido pelo termo "gentrificação"3 , a partir do trabalho da socióloga Ruth Glass (1964), atualizado pelas pesquisas do geógrafo Neil Simth (2006).

\section{A INSTituiÇÃO DOS Sistemas DE PROTEÇÃO DO PATRIMÔNIO CULTURAL BRASILEIRO E PAULISTANO}

No Brasil, as políticas de proteção ao patrimônio histórico ficaram conhecidas pela palavra "tombamento". Este termo surgiu do ato de inventariação dos bens patrimoniais da Coroa Portuguesa que eram inscritos no Livro do Tombo, localizado na torre de mesmo nome. Vem daí a ideia de inscrever os bens de interesse histórico, artístico ou cultural nos livros de tombo para que eles passem a gozar do status de bem protegido. 
Cipriano (2018) afirma que os primeiros estados a criarem seus órgãos de proteção ao patrimônio cultural foram Bahia e Pernambuco, ainda no final dos anos de 1920. Contudo, a criação de um órgão de proteção ao patrimônio nacional só veio durante o governo de Getúlio Vargas (1930-1945), quando o seu ministro da Educação e da Saúde Pública, Gustavo Capanema, chamou o escritor paulistano Mário de Andrade para desenvolver o projeto de criação do órgão federal, visto que ele havia desenvolvido trabalho semelhante no município de São Paulo.

A fim de promover a nova identidade do Estado nacional, que se formava a partir da queda da República Velha, a Constituição Federal de 1934 definiu como obrigação da União, estados e municípios a proteção de objetos de interesse histórico e artístico de relevância para o país. Três anos mais tarde, o Decreto-Lei $n^{\circ} 25$ instituiu pela primeira vez o conceito de patrimônio histórico no Brasil, definindo que o Serviço de Patrimônio Histórico e Artístico Nacional (SPHAN) seria o órgão responsável pelo levantamento, inventariação e catalogação desses bens, assim como pela formulação de políticas para sua proteção.

Conforme o Artigo $1^{\circ}$ dessa Lei (BRASIL, 1937):

Constitue (sic) o patrimônio histórico e artístico nacional o conjunto dos bens móveis e imóveis existentes no país e cuja conservação seja de interêsse (sic) público, quer por sua vinculação a fatos memoráveis da história do Brasil, quer por seu excepcional valor arqueológico ou etnográfico, bibliográfico ou artístico.

O Decreto definiu que o proprietário de coisa tombada seria responsável pela sua conservação. Contudo, se não dispusesse de recursos para proceder às obras de conservação e restauro, ele poderia acionar o SPHAN (atual Instituto do Patrimônio Histórico e Artístico Nacional - Iphan), que deveria executá-las às custas da União. Caso isso não ocorresse no prazo de seis meses, o proprietário poderia requerer o cancelamento do tombamento do bem, conforme o parágrafo $2^{\circ}$ do artigo 19 .

Outra questão definida nesse decreto foi a importância dada ao entorno do bem tombado, pois, conforme o Artigo 18, não se poderia fazer construções na vizinhança do bem tombado que Ihe impedissem ou reduzissem a visibilidade. Além do que, toda construção deveria ser devidamente autorizada pelo órgão. Esse conceito de vizinhança do bem tombado posteriormente resultou no tombamento de grandes áreas urbanas e na formulação de políticas para a sua conservação.

Nos primórdios de sua existência, fase que ficou conhecida como Heroica, o SPHAN concentrou-se no tombamento, restauro e por vezes reconstrução de um patrimônio vinculado ao período colonial brasileiro, procurando reforçar a identidade nacional.

Em 1968, o estado de São Paulo criou seu órgão de tombamento, o Conselho de Defesa do Patrimônio Histórico, Arqueológico, Artístico e Turístico (Condephaat), que passou a tombar e restaurar imóveis remanescentes do passado colonial paulista, principalmente as casas bandeiristas.

Apesar da criação do Condephaat, o município de São Paulo já dispunha de órgão voltado às questões da proteção ao patrimônio histórico desde 1947. 
Através do Decreto-Lei n 430 desse ano, o Departamento de Cultura e Recreação, anteriormente subordinado ao gabinete do prefeito de São Paulo, passou a ser a Secretaria de Educação e Cultura e foi neste período que o órgão, através da Divisão do Arquivo Histórico, iniciou a proteção de edifícios históricos municipais com a preservação das casas bandeiristas do Butantã e do Caxingui (CIPRIANO, 2018).

Apesar da existência dessas ações de proteção aos bens tombados municipais, foi somente em 1972 que uma legislação extensiva procurou proteger uma vasta quantidade de imóveis de interesse histórico na cidade, a partir da criação das Zonas de Uso Especial (Z8-200), definidas na Lei de Zoneamento pela Coordenadoria Geral de Planejamento (Cogep), o órgão de planejamento urbano da prefeitura à época.

Em 1975, foi criado o Departamento do Patrimônio Histórico (DPH) no âmbito da Secretaria Municipal de Cultura (SMC) com uma versão bem próxima da atual, contendo uma divisão técnica específica para preservação, a Divisão Técnica de Preservação, subdividida em duas seções administrativas (Expediente e Laboratório de Restauro) e cinco seções técnicas (SÃO PAULO, 1975):

- STLP - Seção Técnica de Levantamento e Pesquisa;

-STCT - Seção Técnica de Crítica e Tombamento;

-STPRC - Seção Técnica de Projeto, Restauro e Conservação;

-STPR - Seção Técnica de Programas de Revitalização;

-STDP - Seção Técnica de Divulgação e Publicações.

Nesse primeiro momento, a principal função da Divisão de Preservação foi fazer a inventariação dos bens culturais significativos, como subsídio à formulação de legislação de proteção pela Cogep, principalmente em função das

transformações urbanas previstas com a implantação do metrô, que se iniciava (BAFFI, 2006).

Para tanto, foi desenvolvida metodologia de inventariação a partir de uma base geográfica, tendo como unidade os bairros paulistanos, metodologia denominada de Inventário Geral do Patrimônio Ambiental, Cultural e Urbano de São Paulo (Igepac-SP). Os diferentes inventários dos diversos bairros serviriam no futuro para a instrução dos processos de tombamento de imóveis isolados, conjuntos urbanos ou de bairros inteiros.

Considerando que mesmo os imóveis isolados estavam inseridos em uma ambiência urbana, que deveria ser objeto de controle, conforme definia o próprio Decreto-Lei n 15/1937, reafirmado pela instituição das "áreas envoltórias" de 300 metros ao redor do bem protegido, estabelecidas pelo Condephaat, os estudos abrangentes do Igepac demonstraram ser um instrumento adequado para a regulamentação da proteção desses imóveis e dessas áreas urbanas.

Apesar dessa função de suporte à elaboração de uma legislação de proteção cultural, pela própria estrutura definida na lei, é possível supor que a ideia de criação da Divisão de Preservação era que ela tivesse uma postura mais propositiva, participando mais ativamente do processo de preservação e 
4 Um representante dos seguintes órgãos: Secretarias Municipais da Cultura, dos Negócios Jurídicos, do Planejamento, da Habitação e Desenvolvimento Urbano, da Câmara de Vereadores, do Instituto de Arquitetos do Brasil, da Ordem de Advogados do Brasil, do Conselho Regional de Engenharia e Arquitetura, além do diretor do DPH. reabilitação do patrimônio cultural, conforme pode ser visto nas palavras do seu primeiro diretor, o arquiteto Murillo Marx:

Calcada no combate do serviço federal e nos nascentes órgãos estaduais, como o Conselho de Defesa do Patrimônio Histórico, Arqueológico, Artístico e Turístico do Estado - Condephaat, [a Divisão de Preservação] exibe estrutura modelar para o reconhecimento, a proteção e a revitalização de bens culturais e conjuntos urbanos. (MARX, 2006, p. 9-10, grifo nosso).

De fato, essa estrutura possibilitava a atuação completa do órgão, desde os estudos iniciais e inventariação de bens de interesse (STLP) à instrução de processos de tombamento (STCT), análise e proposta de intervenção e conservação dos bens tombados (STPRC), e o desenvolvimento de políticas de revitalização de imóveis ou de áreas urbanas tombados na cidade (STPR). Contudo, faltava ao órgão o poder de deliberação.

Essa ação só foi possibilitada pelas Leis n 10.032, de 1985, e 10.236, de 1986, que criaram e regulamentaram, no âmbito da SMC, o Conselho Municipal de Preservação do Patrimônio Histórico, Cultural e Ambiental Urbano de São Paulo (Conpresp), composto por representantes do poder público e sociedade civil ${ }^{4}$ (SÃO PAULO, 1985, 1986). De acordo com essa legislação, o DPH passaria a ser o órgão técnico a propor e a fiscalizar as ações de proteção ao patrimônio cultural, enquanto o Conpresp seria o órgão político a deliberar sobre os processos de tombamento e, em conjunto com a SMC, "formular as diretrizes e as estratégias necessárias para garantir a preservação dos bens culturais e naturais" (Artigo $8^{\circ}$ da Lei $n^{\circ}$ 10.032/1985 com redação alterada pela Lei $\left.n^{\circ} 10.236 / 1986\right)$.

Para poder efetivar essas políticas, a legislação criou o Fundo Municipal de Preservação do Patrimônio Cultural (Funpac), que contaria com receitas próprias e recursos advindos de multas de danos ao patrimônio. Apesar de a lógica de funcionamento desta estrutura, questões políticas, referentes principalmente à perda do poder dos proprietários sobre seus imóveis tombados, impossibilitaram o funcionamento desse sistema, pois o Conpresp foi criado em 1986 e o Funpac só foi regulamentado 20 anos mais tarde, pelo Decreto $n^{\circ}$ 47.493, de 2006, dificultando assim a efetivação de uma Política Municipal de Reabilitação do Patrimônio Cultural.

\section{As políticas de REABILITAÇÃo Do PATRIMÔNIO Cultural urbano no município de São Paulo}

Apesar da inexistência até 2006, quando o Funpac foi regulamentado, de uma fonte específica de recursos para a efetivação de uma política de reabilitação do patrimônio cultural, algumas ações nesse sentido foram implementadas, porém com uma amplitude nos resultados bastante questionável.

Baseado na influência do advogado John Costonis, que esteve na cidade no final dos anos 1970 difundindo o instrumento TDR, o Município adotou a Transferência de Potencial Construtivo (TPC) na promulgação da Lei n 9.725, de 1984 (SÃO PAULO, 1984), que regulamentou o uso desse instrumento. 
Figura 2 - Casa das Rosas e Edifício Parque Cultural Paulista (torre de vidro)

Fonte: Foto do autor.

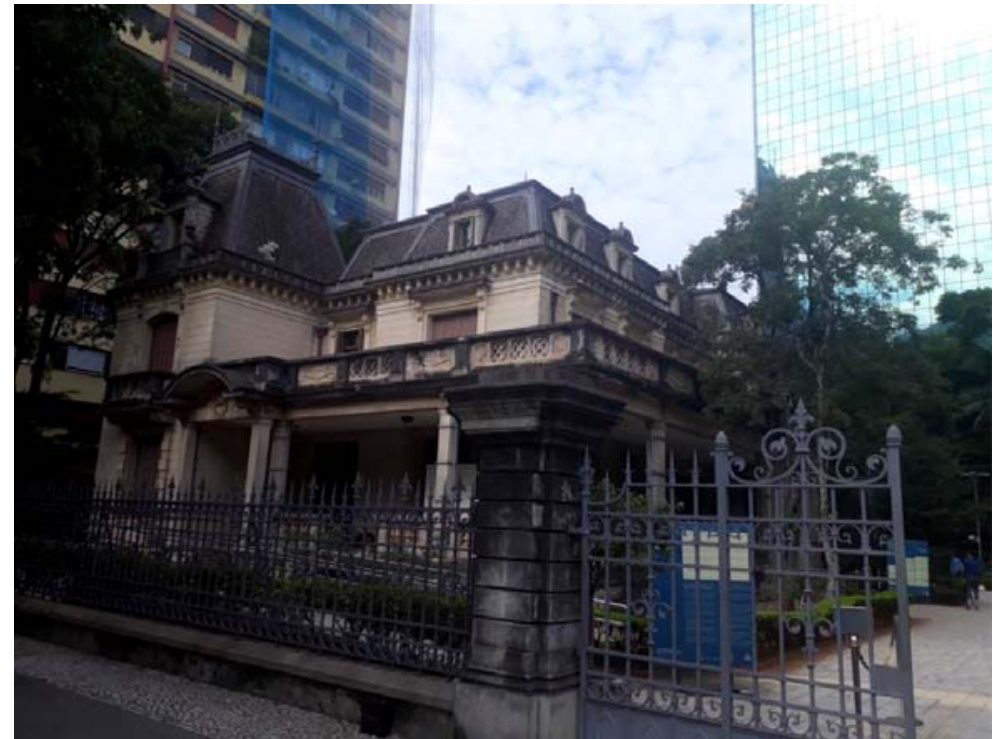

A primeira utilização desse instrumento ocorreu na preservação e recuperação da Casa das Rosas, imóvel localizado na Avenida Paulista, projetado pelo arquiteto Ramos de Azevedo na década de 1930, e que desde 1995 é sede de centro cultural da Secretaria de Estado da Cultura. O potencial construtivo não utilizado da casa foi transferido para o Edifício Parque Cultural Paulista, localizado atrás da casa, na Alameda Santos, conforme Figura 2.

Apesar disso, a utilização dessa lei foi bem aquém do que o esperado pela municipalidade. Segundo Kara-José (2007), foram dois os fatores para que a legislação não tenha sido utilizada conforme se esperava: o primeiro refere-se ao fato de as áreas de entorno às Z8-200 já possuírem, à época, um alto coeficiente de aproveitamento do solo; o segundo, porque, comparativamente, o instrumento era menos atrativo do que outros lançados no mesmo período, como as Operações Interligadas.

Para contribuir na preservação dos edifícios históricos tombados na área central, a Operação Urbana Anhangabaú, regulamentada na Lei n 11.090, de 1991, disponibilizou o mecanismo da Transferência de Potencial Construtivo, que seria calculado pela diferença entre o potencial construtivo do lote e a área nele construída (SÃO PAULO, 1991). A transferência seria autorizada desde que o potencial adquirido não elevasse em mais de $50 \%$ o coeficiente de aproveitamento (CA) da quadra em que se situava o lote. Contudo, essa operação suscitou pouco interesse do mercado, pois, nos seus três anos de vigência, apenas sete termos de compromisso foram assinados, representando a aquisição de $13 \%$ do estoque de área nova (11 mil metros quadrados de área adicional) e a regularização de apenas $6 \%$ do estoque para regularização $(9,6$ mil metros quadrados), resultando na arrecadação de aproximadamente 25 milhões de reais (corrigidos para dezembro de 2018), representando $1 / 5$ dos recursos estimados (NOBRE, 2018).

Da mesma forma, a Operação Urbana Centro, regulamentada pela Lei ${ }^{\circ}$ 12.349 de 1997, instituiu que para imóveis preservados na área central da cidade cujo CA fosse menor ou igual a sete e meio, a transferência poderia ser 
efetuada considerando a diferença entre o potencial do lote e o CA máximo igual a 12. Já os imóveis que tivessem o CA efetivo maior que sete e meio poderiam fazer uso das seguintes regras: se a área construída atingir o limite igual a 12 vezes a área do lote, só poderia transferir uma quantidade de potencial equivalente a $60 \%$; nos casos em que a área construída excedente se encontrasse entre o limite de 12 a 15 vezes a área do lote, o imóvel poderia realizar a transferência de quantidade equivalente a $40 \%$ e, por último, no caso de a área construída exceder 15 vezes a área do lote, o proprietário do imóvel poderia transferir uma quantidade equivalente a $20 \%$ do potencial construtivo de seu imóvel (SÃO PAULO, 1997a).

Ainda no âmbito da Operação Urbana Centro, a prefeitura concedeu isenção de Imposto Predial e Territorial Urbano para os proprietários de imóveis tombados da área que realizassem obras de conservação (cinco anos de isenção) ou restauro (dez anos de isenção) nas suas fachadas, isenção essa regulamentada pela Lei $n^{0} 12.350$, de 1997, conhecida por Lei das Fachadas (SÃO PAULO, 1997b).

Em 22 anos de existência da Operação Urbana Centro, houve 36 pedidos de transferência de potencial construtivo, sendo que apenas cinco foram aprovados (NOBRE, 2018). Desses, quatro foram realizados para lotes que se situavam fora do perímetro dessa operação urbana, algo que em 1999 foi considerado inconstitucional (CIPRIANO, 2018). A Ação Direta de Inconstitucionalidade promovida pelo Ministério Público Estadual alegava que a Lei Municipal não tinha competência para delegar ao Poder Executivo o estabelecimento de normas de zoneamento, uso e ocupação do solo, índices urbanísticos e outras limitações administrativas fora da área da Operação Urbana.

Da mesma forma, a Lei das Fachadas suscitou o interesse de 56 proprietários e até 2003 apenas nove tinham tido sua proposta de restauro aprovada (SÃO PAULO, 1997c, 1997d). Entre as dificuldades de implementação dessa lei, figurava o fato de o restauro ter de ser conforme o projeto original do imóvel, o que dificultava essa ação, tendo em vista a dificuldade de se recuperar as técnicas e os materiais originais. Esse fato fez com que a maior parte dos imóveis que tiveram suas fachadas restauradas pertencesse a instituições que não tinham necessidade do estímulo, pois, em função dos altos custos do restauro, os principais interessados foram bancos e grandes empresas localizadas no centro da cidade.

Posteriormente, o Plano Diretor Estratégico do Município de São Paulo de 2002, (SÃO PAULO, 2002a) ampliou a utilização desses instrumentos ao estabelecer as Zonas Especiais de Preservação Cultural (Zepec), que foram modificadas e mais bem detalhadas no Plano de 2014 (SÃO PAULO, 2014) em quatro tipos:

1. Bens Imóveis Representativos (BIR) - elementos construídos, edificações e suas respectivas áreas ou lotes, com valor histórico, arquitetônico, paisagístico, artístico, arqueológico e/ou cultural;

2. Áreas de Urbanização Especial (AUE) - porções do território com características singulares do ponto de vista da morfologia urbana, arquitetônica, paisagística, do ponto de vista cultural e simbólico, ou 


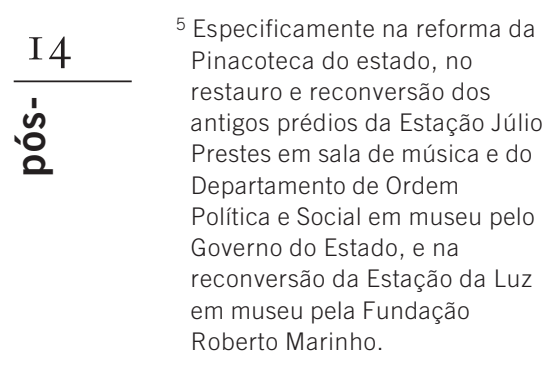

Especificamente na reforma da Pinacoteca do estado, no antigos prédios da Estação Júlio Prestes em sala de música e do artamento de Ordem Governo do Estado, e na em museu pela Fundação Roberto Marinho. conjuntos urbanos dotados de identidade e memória, possuidores de características homogêneas quanto ao traçado viário, vegetação e índices urbanísticos, que constituem documentos representativos do processo de urbanização de determinada época;

3. Áreas de Proteção Paisagística (APPa) - sítios e logradouros com características ambientais, naturais ou antrópicas, como parques, jardins, praças, monumentos, viadutos, pontes, passarelas e formações naturais significativas, áreas indígenas, entre outras;

4. Área de Proteção Cultural (APC) - imóveis de produção e fruição cultural, destinados à formação, produção e exibição pública de conteúdos culturais e artísticos, como teatros e cinemas de rua, circos, centros culturais, residências artísticas e assemelhados, cuja proteção é necessária à manutenção da identidade e da memória do município e de seus habitantes.

Esse último plano regulamentou a agora chamada Transferência do Direito de Construir (TDC) para os imóveis inseridos nas Zepec-BIR e APC, assim como a sua fórmula de cálculo, possibilitando a transferência do potencial construtivo para imóveis receptores para toda a Macrozona Urbana, onde o CA da zona permitisse. Mediante anuência do Conpresp, essa transferência pode ser realizada e os recursos advindos, utilizados na conservação do imóvel tombado.

Em 2018, dos mais de três mil imóveis tombados, apenas 182 (cerca de 6\%) possuíam a Declaração de Potencial Construtivo Passível de Transferência emitida e desses, apenas 35 já haviam transferido o seu potencial construtivo (PERETTO et al., 2018). A maior parte das transferências foi proveniente das áreas centrais da cidade, que concentram os imóveis tombados, e foi transferida para os bairros do Quadrante Sudoeste paulistano, conforme definição de Villaça (1998), região onde se concentra boa parte da elite paulistana e onde o preço da terra é o mais valorizado da cidade.

Além das experiências com a TDC, outra política com objetivo de recuperação do patrimônio cultural desenvolvida na cidade de São Paulo foi o Programa Monumenta. Criado no âmbito do Ministério da Cultura em 1995, o Programa contava com apoio do Banco Interamericano de Desenvolvimento (BID), tendo por objetivo o resgate e a conservação permanente dos principais conjuntos patrimoniais urbanos do Brasil.

Influenciado por conceitos neoliberais, o Programa trazia um componente financeiro importante, pois o objetivo era desenvolver uma estratégia de conservação sustentável, baseada na atuação da iniciativa privada na promoção de atividades turísticas e comerciais, que resultariam na valorização imobiliária do patrimônio e o consequente interesse dos proprietários em sua conservação (DUARTE JÚNIOR, 2010). Dessa forma, o Programa pretendia desonerar o Estado dos ônus da conservação e efetivá-la através da ação dos proprietários, comerciantes e investidores.

Na capital paulista, a região definida para ser objeto do programa foi o entorno da Estação da Luz, no Centro de São Paulo, região que já vinha recebendo investimentos do Governo do Estado e de entidades privadas em projetos de grandes equipamentos culturais desde a década de $1990^{5}$, numa tentativa de reverter sua desvalorização simbólica e imobiliária. 


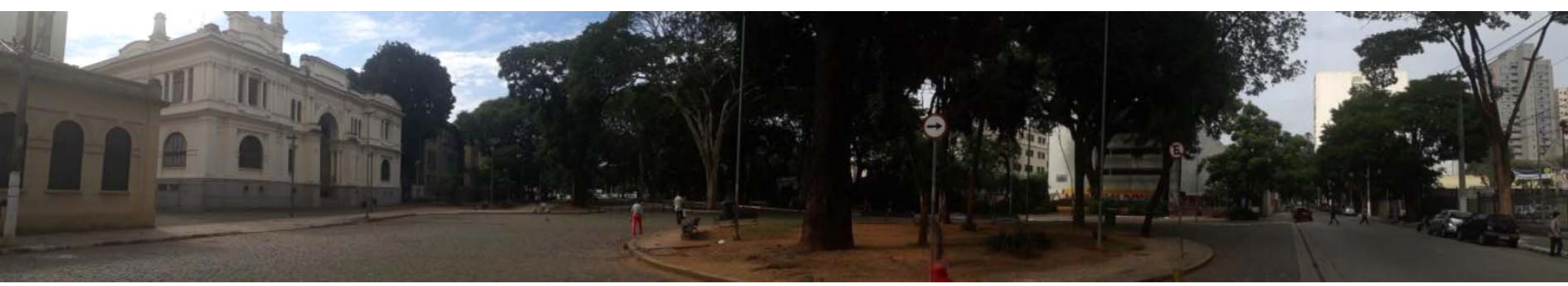

Figura 3 - Praça Coronel Fernando Prestes e Edifício Ramos de Azevedo após reforma e restauro

Fonte: Foto do autor.

${ }^{6}$ As cinco linhas do Ação Centro eram: reversão da desvalorização imobiliária e recuperação da função residencial; transformação do perfil econômico e social; recuperação do ambiente urbano; transporte e circulação; e fortalecimento institucional do município.

7 O plano Reconstruir o Centro foi elaborado pela Administração Regional da Sé e Comissão do Procentro em 2001 e previa setes programas principais: Andar no Centro; Morar no Centro; Trabalhar no Centro; Descobrir o Centro; Preservar o Centro; Investir no Centro e Cuidar do Centro (SÃO PAULO, 2001).

8 Especificamente o Solar da Marquesa de Santos, a Casa Número 1 e o Beco do Pinto, além do Museu do Teatro Municipal.
O convênio entre o Ministério da Cultura e as secretarias de cultura do município e do Estado foi assinado em 2002, prevendo valor inicial de 20 milhões de reais, que seriam divididos entre o BID (50\%), Ministério da Cultura (20\%), Secretaria de Estado da Cultura (15\%) e Secretaria Municipal da Cultura (15\%), e que seriam investidos na recuperação do espaço público (reforma da Praça Coronel Fernando Prestes e de equipamentos do Parque da Luz), nas obras de restauro de edifícios públicos e edifícios religiosos (Edifício Ramos de Azevedo, Paula Souza e Museu de Arte Sacra), conforme Figura 3, e na reforma de edifícios privados.

Em 2006 foram lançados dois editais de seleção de imóveis privados, que contariam com uma linha de financiamento de até 1,9 milhões de reais para sua reforma e restauro (DIOGO, 2009; BONDUKI, 2010). Contudo, não houve grande interesse por parte dos proprietários de contratar esse empréstimo, demonstrando que, no caso de São Paulo, o Programa não logrou transformar a área, que já vinha sendo alvo de programas semelhantes desde os anos 1970 sem nenhum sucesso.

Por fim, a Prefeitura de São Paulo lançou o Programa de Reabilitação da Área Central do Município de São Paulo: Ação Centro, também com financiamento do BID, em 2003. Apesar de as linhas de ação do Programa negociadas com o BID não estarem diretamente relacionadas com a questão de recuperação do patrimônio histórico ${ }^{6}$, o programa era baseado no Plano Reconstruir o Centro ${ }^{7}$, que tinha na ação Preservar o Centro esse objetivo (SÃO PAULO, 2001).

O Programa funcionou mais como um guarda-chuva para orquestrar uma série de ações que já estavam ou viriam a ser tomadas pelas diversas secretarias da municipalidade. As ações atinentes ao patrimônio histórico estavam relacionadas com a implantação do Programa Museológico do Museu da Cidade, projeto da Divisão de Iconografia e Museus do DPH (DIM/DPH), para criação de um Sistema Municipal de Museus (BRUNO, 2006). Nesse aspecto, as ações do DPH/SMC relativas ao Programa estavam relacionadas à reforma de imóveis municipais que faziam parte desse sistema localizados na área central e que sediavam a DIM ${ }^{8}$.

Posteriormente, em função da descontinuidade administrativa, o Programa Ação Centro foi redirecionado para o Projeto Nova Luz, sob o pretexto de que seria necessário concentrar esforços e investimentos em uma área menor para que sua renovação se irradiasse para o entorno, processo esse definido pelo arquiteto Jaime Lerner, consultor do projeto, como "acupuntura urbana". Esse 
projeto pouco tinha a ver com a reabilitação do patrimônio cultural, pois se baseava num ideal de renovação urbana tábula rasa, a partir da atuação do mercado imobiliário via concessão urbanística de imóveis desapropriados em 24 quadras no entorno da Estação da Luz.

\section{CONSIDERAÇÕES FINAIS}

Passados mais de 40 anos da criação do DPH e mais de 30 do Conpresp, é possível ter uma boa análise da efetividade desses órgãos na promoção de políticas de proteção e recuperação do patrimônio cultural paulistano.

Durante esse período, esses órgãos promulgaram mais de 500 resoluções relativas a processos de tombamento de acervos artísticos e arquivísticos, imóveis isolados ou em conjunto, parques e áreas verdes, quadras e bairros da cidade de São Paulo, resultando no tombamento de 3.559 edifícios dos mais diversos tipos (casas, conjuntos residenciais, hospitais, escolas, clubes, prédios públicos, fábricas, estações rodo-metro-ferroviárias, sítios etc.), 14 parques e praças e dez bairros tombados, envolvendo mais de um milhão de munícipes (SOMEKH, 2016).

Contudo, se do ponto de vista do estabelecimento de uma normativa de proteção ao patrimônio cultural esses órgãos foram efetivos, o mesmo não pode ser dito do ponto de vista de políticas de conservação e reabilitação desse patrimônio.

Em que pese o fato de o DPH dispor de uma Seção Técnica de Programas de Revitalização, recentemente renomeada para Seção Técnica de Programas de Valorização do Patrimônio, a demora de 20 anos na implementação do Funpac, entre outras coisas, fez com que esses órgãos adotassem uma postura muito mais restritiva do que proativa, pois não dispunham nem de recursos para efetivar os programas de recuperação.

A falta de um projeto de reabilitação integrada para as áreas tombadas acabou por não viabilizar sua conservação e restauro. Nesse aspecto, várias regiões da cidade que foram fruto de resoluções de tombamento, como o Vale do Anhangabaú (SÃO PAULO, 1992), Bela Vista (SÃO PAULO, 2002b) e Centro Velho (SÃO PAULO, 2007) poderiam ter sido alvo de projetos específicos que buscassem sua reabilitação, nos moldes das intervenções feitas em Bolonha, ou nos moldes dos planos propostos no âmbito do Programa de Reabilitação de Áreas Centrais, desenvolvidos pelo extinto Ministério das Cidades para cidades como Belém, Belo Horizonte, Porto Alegre, Rio de Janeiro e Salvador entre 2004 e 2011, que procurou conjugar a reabilitação integrada de centros históricos com a promoção de habitação de interesse social (BRASIL, 2008).

Mesmo programas mais abrangentes como o Monumenta e Ação Centro, ambos financiados pelo BID, não lograram promover essa reabilitação integrada, tendo em vista que os objetivos principais de ambos estavam mais relacionados à valorização imobiliária das regiões de abrangência do que na recuperação, reabilitação física e, principalmente, simbólica dos imóveis de interesse

cultural. Por outro lado, o resultado inexpressivo desses programas em São Paulo pode ser comemorado, pois caso tivessem obtido êxito, certamente teriam ocasionado um efeito "gentrificador" em suas áreas de influência. 
9 O Fundo Municipal de Saúde foi responsável por $73 \%$ desse valor.
Além da ausência dessa ação integrada do Poder Público, o grande empecilho para a implementação de políticas urbanas de reabilitação do patrimônio cultural em São Paulo parece ser de cunho financeiro, seja pela reação dos proprietários à perda do valor imobiliário dos imóveis tombados, seja pelos altos custos envolvidos para seu restauro e conservação.

De qualquer forma, os dados relativos ao orçamento municipal não nos levam a crer que a atuação pública na recuperação do patrimônio cultural paulistano vá aumentar no futuro próximo, pois dados da Secretaria Municipal de Fazenda informam que o orçamento da SMC representa apenas 1,1\% dos R $\$ 51$ bilhões de despesas da prefeitura em 2017, sendo que as despesas obrigatórias (Educação, Saúde e Previdência) representaram 60\% (SÃO PAULO, 2018).

Já o Funpac representou apenas $0,004 \%$ dos $\mathrm{R} \$ 11,7$ bilhões dos fundos municipais $^{9}$, sendo que nada foi gasto em 2017 dos $\mathrm{R} \$ 463$ mil alocados. $E$ mesmo o Fundo de Desenvolvimento Urbano (Fundurb), que apresentou $\mathrm{R} \$$ 125 milhões $(1,06 \%)$, não tem tido propostas de projetos relacionados à recuperação do patrimônio cultural, com exceção do restauro do Edifício Sampaio Moreira, futura sede da SMC.

A reabilitação baseada na iniciativa dos proprietários tampouco logrou, pois a proposta de adoção da TDC ou TPC como forma de diminuir a forte reação dos proprietários dos imóveis protegidos através da compensação financeira pela perda do valor imobiliário apresentou poucos resultados até o momento.

Contudo, a grande especulação recente no mercado de direitos construtivos pode apontar para mudanças nesse aspecto. O exemplo do Parque Augusta, o qual as incorporadoras de um grande empreendimento imobiliário cederam o terreno para a prefeitura criar o citado parque em troca de $\mathrm{R} \$ 205$ milhões de isenções de pagamento de Outorga Onerosa do Direito de Construir de empreendimentos futuros, parece demonstrar que a securitização dos direitos de construir pode constituir-se um forte mercado para viabilizar determinadas ações públicas.

O fato de o valor do terreno em tela ser de apenas $\mathrm{R} \$ 110$ milhões, ou seja, metade do valor da renúncia fiscal por parte da prefeitura, demonstra a discrepância entre o interesse público e o lucro privado na criação desse equipamento público. Dessa forma, se a recuperação do patrimônio cultural ocorrer a partir de experiências semelhantes de securitização dos direitos de construir, há que se perguntar "a que preço?". Mais do que nunca, é necessária uma ação integrada do Poder Público nesse processo.

\section{REFERÊNCIAS}

APPLEYARD, Donald. The conservation of European cities. Cambridge: MIT Press, 1979.

BAFFI, Mirthes I. S. O IGEPAC-SP e outros inventários da Divisão de Preservação do DPH: um balanço. Revista do Arquivo Municipal, São Paulo, v. 204, p. 169-191, 2006.

BONDUKI, Nabil G. Intervenções urbanas na recuperação de centros históricos. Brasília, DF: IPHAN: Programa Monumenta, 2010.

BRASIL. Decreto-Lei $n^{\circ}$ 25, de 30 de novembro de 1937. Organiza a proteção do Patrimônio Histórico e Artístico Nacional. Presidência da República: Casa Civil: subchefia para assuntos jurídicos: legislação, 1937. Disponivel em: https://bit.ly/2H2FRWu. Acesso em: 28 nov. 2018. 
BRASIL. [Constituição (1988)]. Constituição da República Federativa do Brasil de 1988, Brasília, DF: Presidência da República, 1988. Disponível em: https://bit.ly/1bJYIGL. Acesso em: 12 ago. 2019.

BRASIL. Manual de reabilitação de áreas urbanas centrais. Brasília, DF: Ministério das Cidades: Agência Espanhola de Cooperação Internacional, 2008.

BRUNO, Maria Cristina Oliveira. Museu da Cidade de São Paulo: as mudanças éticas sonhadas por Mário de Andrade. Revista do Arquivo Municipal, São Paulo, v. 204, p. 119-128, 2006.

CERVELLATI, Pier Luigi; SCANNAVINI, Roberto; ANGELIS, Carlo De. La nuova cultura delle citta: la salvaguardia dei centri storici, la riappropriazione sociale degli organismi urbani e l'analisi dello sviluppo territoriale nell'esperienza di Bologna. Milão: Mondadori, 1977.

CERVELLATI, Pier Luigi. Risanamento conservativo del cento storico di Bologna. Bolonha: Graficoop, 1979.

CHOAY, Françoise. A alegoria do patrimônio. São Paulo: Estação Liberdade: Editora Unesp, 2001.

CIPRIANO, Dulcilei Souza. A transferência de potencial construtivo: incentivo a conservação dos edifícios protegidos na área central de São Paulo (?). 2018. Dissertação (Mestrado em Arquitetura e Urbanismo) - Faculdade de Arquitetura e Urbanismo, Universidade de São Paulo, São Paulo, 2018.

CONSELHO INTERNACIONAL DE MONUMENTOS E SÍTIOS ESCRITÓRIO (Icomos). Carta de Veneza. In: CONGRESSO INTERNACIONAL DE ARQUITETOS E TÉCNICOS DOS MONUMENTOS HISTÓRICOS, 2., 1964, Veneza. Anais [...]. São Paulo: Iphan, 2001. Disponivel em: https://bit.ly/2uzqb69. Acesso em: 28 nov. 2018.

COSTONIS, John. Space adrift: landmark preservation and the market place. Champaign: University of Illinois Press, 1974.

DIOGO, Érica. Recuperação de imóveis privados em Centros Históricos. Brasília, DF: Iphan: Programa Monumenta, 2009.

DUARTE JÚNIOR, Romeu. Programa Monumenta: uma experiência em preservação urbana no Brasil. Revista CPC, São Paulo, v. 10, p. 49-88, 2010.

ESCRITÓRIO INTERNACIONAL DOS MUSEUS SOCIEDADE DAS NAÇÕES. Carta de Atenas. São Paulo: Iphan, 2001. Disponivel em: https://bit.ly/2X×2eOh. Acesso em: 28 nov. 2018.

FRANÇA. Lei n 62-903 de 4 de agosto de 1962. Completánt la législation sur la protection du patrimoine historique et esthétique de la France et tendant à faciliter la restauration immobilière. Journal Officiel de la Republique Française, Paris, p. 7913-7915, 7 out. 1962.

GLASS, Ruth. L. London: aspects of change. London: McGibbon \& Kee, 1964.

HISTORIC preservation in the American city: a New York case study. Law and Contemporary Problems, Durham, v. 36, n. 3, p. 362-385, 1971.

INSTITUTO DO PATRIMÔNIO HISTÓRICO E ARTÍSTICO NACIONAL (Iphan). Carta de Atenas. In: CONGRESSO INTERNACIONAL DE ARQUITETURA MODERNA, 1933, Atenas. Anais [...]. São Paulo: Iphan, 2001. Disponivel em: https://bit.ly/2KDOfuV. Acesso em: 28 nov. 2018.

INTERNATIONAL COUNCIL ON MONUMENTS AND SITES (Icomos). The Burra Charter. Burwood: The Australia Icomos, 2013. Disponivel em: https://bit.ly/2vQbVGQ. Acesso em: 28 nov. 2018.

KARA-JOSÉ, Beatriz. Políticas culturais e negócios urbanos: a instrumentalização da cultura na revalorização do centro de São Paulo (1975-2000). São Paulo: Annablume: Fapesp, 2007.

KÜHL, Beatriz. M. Observações sobre os textos de Gustavo Giovannoni traduzidos nesta edição. In: KÜHL, Beatriz Mugayar (org.). Gustavo Giovannoni. Textos Escolhidos. Cotia: Ateliê Editorial, 2012. p. 11-30.

MARX, Murillo. Depoimento. Revista do Arquivo Municipal, São Paulo, v. 204, p. 9-10, 2006.

NOBRE, Eduardo Alberto Cusce. Towards a better approach to urban regeneration: defining strategies for intervention in the central area of São Paulo. 1994. Dissertação (Mestrado em Desenho Urbano) - Joint Centre for Urban Design, Oxford Brookes University, Oxford, 1994.

NOBRE, Eduardo Alberto Cusce. Do Plano Diretor às Operações Urbanas Consorciadas: a ascensão do discurso neoliberal e dos grandes projetos urbanos no planejamento paulistano. 2018. Tese (Livre-Docência em Arquitetura e Urbanismo) - Faculdade de Arquitetura e Urbanismo, Universidade de São Paulo, São Paulo, 2018. 
OLIVEIRA, Carolina Fidalgo. Do tombamento às reabilitações urbanas: um estudo sobre a preservação no Centro Histórico de São Paulo (1970-2007). 2009. Dissertação (Mestrado em Arquitetura e Urbanismo) - Faculdade de Arquitetura e Urbanismo, Universidade de São Paulo, São Paulo, 2009.

ORGANIZAÇÃO DAS NAÇÕES UNIDAS PARA A EDUCAÇÃO, A CIÊNCIA E A CULTURA (Unesco). Convenção para a protecção do património mundial, cultural e natural. Paris: Unesco, 1972. Disponivel em: https://bit.ly/2V32Buv. Acesso em: 14 jun. 2019.

ORGANIZAÇ̃̃O DOS ESTADOS AMERICANOS (OEA). Normas de Quito. In: REUNIÃO SOBRE A CONSERVAÇÃO E UTILIZAÇÃO DE MONUMENTOS E LUGARES DE INTERESSE HISTÓRICO E ARTÍSTICO. Quito, 1967. Anais [...]. São Paulo: Iphan, 2001. p. 1-14. Disponivel em: https:// bit.ly/2kASA9o. Acesso em: 28 nov. 2018.

ORGANIZAÇÃO PARA A COOPERAÇÃO E DESENVOLVIMENTO ECONÔMICO. (OECD). Managing urban change. Paris: OECD, 1983.

PERETTO, Flávia Taiberti et al. Quando a transferência de potencial construtivo virou mercado: o caso de São Paulo. In: SEMINÁRIO DE HISTÓRIA DA CIDADE E DO URBANISMO, 15., 2018, Rio de Janeiro. Anais [...]. Rio de Janeiro: Anpur: UFRJ, 2018. p. 1-22.

RAPKIN, Chester. An evaluation of the urban renewal experience in the USA. In: KOENIGSBERGER, Otto (org.). The work of Charles Abrams: housing and urban renewal in the USA and the Third World. Oxford: Pergamon Press, 1980. p. 181-192.

SÃO PAULO (Município). Lei no 8.252, de 20 de maio de 1975. Dispõe sobre a criação do Departamento de Informação e Documentação Artística, e dá outras providências. São Paulo, município: Câmara Municipal de São Paulo, 1975. Disponivel em: https://bit.ly/2ZX7fN5. Acesso em: 26 mar. 2019.

SÃO PAULO (Município). Lei n 9.725, de 2 de julho de 1984. Dispõe sobre a transferência de potencial construtivo de imóveis preservados; estabelece incentivos, obrigações e sanções relativas à preservação de imóveis, e dá outras providências. Diário Oficial do Município, São Paulo, p. 5-7, 3 jul. 1984.

SÃO PAULO (Município). Lei n 10.032, de 27 de dezembro de 1985. Dispõe sobre a criação de um Conselho Municipal de Preservação do Patrimônio Histórico, Cultural e Ambiental da Cidade de São Paulo. Diário Oficial do Município, São Paulo, 28 dez. 1985.

SÃO PAULO (Município). Lei n 10.236 , de 16 de dezembro de 1986. Altera dispositivos da Lei n 10.032 , de 27 de dezembro de 1985, que dispõe sobre a criação do CONPRESP. Diário Oficial do Município, São Paulo, p. 4, 17 dez. 1986.

SÃO PAULO (Município). Lei n 11.090, de 16 de setembro de 1991. Estabelece programa de melhorias para a área de influência imediata do Vale do Anhangabaú, cria incentivos e formas para sua implantação, e dá outras providências. Diário Oficial do Município, São Paulo, p. 1-2, 17 set. 1991.

SÃO PAULO (Município). Conselho Municipal de Preservação do Patrimônio Histórico, Cultural e Ambiental da Cidade de São Paulo. Resolução n 37, de 9 de dezembro de 1992. São Paulo: Conpresp, 1992. Disponível em: https://bit.ly/2Z43eVM. Acesso em: 13 ago. 2019.

SÃO PAULO (Município). Lei n 12.349, de 6 de junho de 1997. Estabelece programa de melhorias para a área central da cidade, cria incentivos e formas para a sua implantação, e dá outras providências. Diário Oficial do Município, São Paulo, p. 1-2, 7 jun. 1997a.

SÃO PAULO (Município). Lei $n^{\circ}$ 12.350, de 6 de junho de 1997. Concede incentivo fiscal aos proprietários de imóveis ou aos patrocinadores das obras de recuperação externa e conservação de imóveis localizados na Área Esp. de Intervenção, objeto do Programa de Req. Urb.-PROCENTRO. Diário Oficial do Município, São Paulo, p. 2-4, 7 jun. 1997b.

SÃO PAULO (Município). Lei n 12.349, de 6 de junho de 1997. Estabelece programa de melhorias para a área central da cidade, cria incentivos e formas para sua implantação, e dá outras providências. Diário Oficial do Município, São Paulo, 7 jun. 1997c. Disponível em: https:// bit.ly/33reKOt. Acesso em: 13 ago. 2019.

SÃO PAULO (Município). Lei n 12.350, de 6 de junho de 1997. Concede incentivo fiscal aos proprietários de imóveis ou aos patrocinadores das obras de recuperação externa e conservação de imóveis localizados na Área Especial de Intervenção, objeto do Programa de Requalificação Urbana e Funcional do Centro de São Paulo - PROCENTRO, ou outro equivalente que venha a ser implantado, e dá outras providências. Diário Oficial do Município, São Paulo, 7 jun. 1997d. Disponível em: https://bit.ly/2yWJh8K. Acesso em: 13 ago. 2019. 
SÃO PAULO (Município). Reconstruir o Centro: reconstruir a cidade e cidadania. São Paulo: Administração Regional da Sé: Procentro, 2001.

SÃO PAULO (Município). Lei $n^{\circ}$ 13.430, de 13 de setembro de 2002. Institui o Plano Diretor Estratégico do município de São Paulo e dá outras providências. Diário Oficial do Município, São Paulo, p. 1-13, 14 set. 2002a.

SÃO PAULO (Município). Conselho Municipal de Preservação do Patrimônio Histórico, Cultural e Ambiental da Cidade de São Paulo. Resolução no 22, de 2002. São Paulo: Conpresp, 2002b. Disponível em: https://bit.ly/2ySTCmb. Acesso em: 13 ago. 2019.

SÃO PAULO (Município). Conselho Municipal de Preservação do Patrimônio Histórico, Cultural e Ambiental da Cidade de São Paulo. Resolução no 22 de 17 de julho de 2007. São Paulo: Conpresp, 2007. Disponível em: https://bit.ly/2YMH6E4. Acesso em: 13 ago. 2019.

SÃO PAULO (Município). Lei $n^{\circ}$ 16.050, de 31 de julho de 2014. Aprova a Política de Desenvolvimento Urbano e o Plano Diretor Estratégico do Município de São Paulo e revoga a Lei n 13.430/2002. Diário Oficial do Município, São Paulo, p. 1-352, 1 ago. 2014.

SÃo PAULO (Município). Relatório técnico do balanço geral de 2017. São Paulo: Secretaria Municipal da Fazenda, 2018.

SMITH, Neil. A gentrificação generalizada: de uma anomalia local à "regeneração" urbana como estratégia urbana global. In: BIDOU-ZACHARIASEN, Catherine. De volta à cidade: dos processos de gentrificação às políticas de "revitalização" dos centros urbanos. São Paulo: Annablume, 2006. p. 59-87.

SOMEKH, Nádia. Inovações na gestão do patrimônio cultural em São Paulo. In: COLÓQUIO BRASIL-PORTUGAL, 4., 2016, São Paulo. Anais [...].São Paulo: Universidade Presbiteriana Mackenzie, 2016. p. 1-15.

SUSSKIND, Lawrence; ELLIOTT, Michael. Paternalism, conflict and coproduction. New York: Plenum Press, 1983.

VILLAÇA, Flávia. Espaço intra-urbano no Brasil. São Paulo: Studio Nobel: Fapesp: Lincoln Institute, 1998.

\section{Nota do Autor}

Este artigo apresenta resultados parciais de Projeto de Pesquisa Regular financiado pela Fundação de Amparo à Pesquisa do Estado de São Paulo (Fapesp) (Processo no 2017/15.256-1) e pelo Edital Universal do Conselho Nacional de Desenvolvimento Científico e Tecnológico (CNPq) (Processo $\mathrm{n}^{\circ}$ 423.981/2018-8).

\section{Nota do Editor}

Data de submissão: 13/05/2019

Aprovação: 13/06/2019

Revisão: Tikinet

\section{Eduardo Alberto Cusce Nobre}

Universidade de São Paulo. Faculdade de Arquitetura e Urbanismo.

Rua do Lago, 876, Butantã, 05508-970, São Paulo, SP

ORCID: https://orcid.org/0000-0002-8127-5510

eacnobre@usp.br 